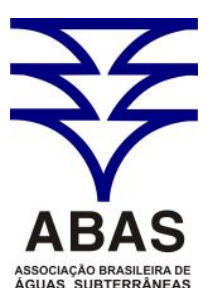

ASSOCIACÃO BRASILEIRADE
AGGUAS SUBTERRANEAS www.abas.org

\title{
KIT ANALÍTICO SIMPLIFICADO: UMA FERRAMENTA PARA AVALIAÇÃO MASSIVA DA QUALIDADE DA ÁGUA SUBTERRÂNEA
}

\author{
SIMPLIFIED WATER TEST KIT: A TOOL FOR LARGE-SCALE \\ ANALYSIS OF THE GROUNDWATER QUALITY
}

\author{
Maria da Graça Zepka Baumgarten¹, Mariele Lopes de Paiva², \\ Horácio Rodrigo Souza Rodrigues ${ }^{3}$
}

Artigo recebido em: 30/05/2014 e aceito para publicação em: 08/10/2014.

\begin{abstract}
Groundwater resources constitute an important alternative supply. However, the physic - chemical conditions in the subterranean environment favoring the dissolution of some compounds, including iron. This element, when present in excess in the water for residential use can lead to poor quality of life and health. In this context, this paper presents a method for the preparation and handling of a simplified water test kit, optimized for the qualitative determination of dissolved iron in the water. The method principle is based on visual colorimetry, wherein the sample becomes colored by the addition of reactants, allowing the comparison with a color chart and its associated iron levels. The use of this tool can facilitate, for example, making diagnoses of water quality by a massive evaluation of the water used in communities without access to safe water. This water test kit was applied as a diagnostic tool in an area where there is no supply of drinking water, in Rio Grande city - RS. Of the 309 households assessed, on average $47 \pm 23 \%$ is supplied by rusty water. These results enabled the awareness and mobilization of the residents, as well as the performance of public agencies to develop strategies for improving the quality of water consumed by the population.
\end{abstract}

Keywords: Iron analysis. Potability. Rust water. Qualitative method.

Resumo: Os recursos hídricos subterrâneos configuram uma importante alternativa de abastecimento. Porém, as condições físico-químicas no ambiente subterrâneo favorecem a dissolução de alguns compostos, entre eles o ferro. Esse elemento, quando presente em excesso na água para consumo residencial, pode acarretar problemas de qualidade de vida e de saúde. Nesse contexto, o presente trabalho apresenta um método para a elaboração e manuseio de um kit analítico simplificado, otimizado para a determinação qualitativa do ferro dissolvido na água. Esse instrumento é fundamentado na colorimetria visual, na qual a adição de reagentes confere cor à amostra, permitindo sua comparação com uma cartela de cores contendo níveis de contaminação associados aos diferentes tons da cor laranja. A utilização desta ferramenta pode facilitar a elaboração de diagnósticos da qualidade da água, através da avaliação massiva da água subterrânea consumida em comunidades desprovidas de água potável canalizada. Este kit analítico foi aplicado como ferramenta de diagnóstico em uma área sem suprimento de água potável em Rio Grande - RS. Das 309 residências avaliadas, em média $47 \pm 23 \%$ são abastecidas por água ferruginosa. Esses resultados possibilitaram a conscientização e mobilização dos moradores da área, bem como a atuação dos órgãos públicos na elaboração de estratégias para a melhoria na qualidade da água consumida pela população.

Palavras-chave: Análise de ferro. Potabilidade. Água ferruginosa. Método qualitativo.

\section{INTRODUÇÃO}

Devido à crescente escassez de água que atinge grande parte da população mundial, os recursos hídricos subterrâneos têm se tornado uma importante alternativa de abastecimento. Apesar de uma maior proteção dos contaminantes externos, as águas subterrâneas podem apresentar problemas de qualidade e, dentre esses, um dos mais frequentes consiste na presença de ferro em concentrações elevadas (água ferruginosa), limitando algumas vezes, a utilização da água tanto para uso doméstico como industrial (LIMA e PEDROZO, 2001).

O ferro é um dos metais mais abundantes na crosta terrestre. Ele ocorre naturalmente na água na forma solúvel, predominantemente ferrosa $\left(\mathrm{Fe}^{+2}\right)$, ou em formas oxidadas de ferro férrico $\left(\mathrm{Fe}^{+3}\right)$, de menor solubilidade. Condições redutoras e anóxicas ou semi-anóxicas acarretam na

\footnotetext{
${ }^{1}$ Universidade Federal do Rio Grande, FURG, Rio Grande, RS (dqmmgzb@ furg.br).

2 Universidade Federal do Rio Grande, FURG, Rio Grande, RS (marieledepaiva @ gmail.com).

${ }^{3}$ Universidade Federal do Rio Grande, FURG, Rio Grande, RS (horacio.rodrigues@ furg.br).
} 
ausência de cor da água, mesmo quando esta contém excesso de ferro, pois esse elemento geralmente se mantém no estado solúvel e incolor nestas condições. Porém, em ambientes oxidantes forma-se o ferro trivalente, predominantemente insolúvel, que confere à água um aspecto amarelado, devido à formação de pequenos flocos ferruginosos (LIMA e PEDROZO, 2001).

Os óxidos de ferro atuam como carreadores de outros metais, principalmente aqueles de valência constante $(\mathrm{Co}, \mathrm{Ni}, \mathrm{Cu}, \mathrm{Pb}, \mathrm{Zn})$, e assim, suas presenças frequentemente são associadas a de muitos outros metais ainda mais tóxicos (VODYANITSKII e PLEKHANOVA, 2014).

A ingestão de ferro em doses moderadas tem um efeito positivo à saúde humana, pois é um nutriente essencial para o metabolismo normal das células. Em humanos, a sua carência pode causar anemia ferropriva e outras disfunções. Mas em quantidades elevadas, o ferro pode ser tóxico (CORBETT, 1995; BALMADRID e BONO, 2009), já que quando metabolizado excessivamente, afeta quase todos os órgãos humanos, em função de sua toxicidade intracelular sistêmica, podendo aumentar a incidência de problemas cardíacos e diabetes (ROBERTSON e TENENBEIN, 2006; SKOCZYNSKA et al., 2007).

Devlin (2007) afirma que o acúmulo excessivo de ferro no fígado, no pâncreas e no coração pode levar a cirrose e tumores hepáticos, Diabetes mellitus e insuficiência cardíaca, respectivamente. Ainda, Mahan (2004) relaciona a ingestão de ferro em demasia à formação de um exces-

so de radicais livres no organismo, que prejudica o equilíbrio das moléculas celulares.

O Painel sobre Micronutrientes da Junta de Alimentação e Nutrição Americana ( $F O O D$ AND NUTRITION BOARD, 1989) definiu o nível de ingestão humana máxima de ferro como $45 \mathrm{mg}$ $\operatorname{dia}^{-1}$, o que varia em função do sexo, idade e condição fisiológica. Além do consumo de alimentos ricos em ferro, como carnes e vegetais, um indivíduo adulto deve consumir em média dois litros de água por dia. Assim, considerando que as águas ferruginosas podem apresentar máximos que vão de 10 até $50 \mathrm{mg} \mathrm{L}^{-1}$ de ferro (LIMA e PEDROZO, 2001), se este indivíduo somente dispor desse tipo de água para consumo e não adotar mecanismos de tratamento da água (caseiros ou não), isso acarretará em um acúmulo de ferro no organismo.

Nesse contexto, comunidades que consomem águas ferruginosas são rotineiramente submetidas ao risco de intoxicação por ferro. Além das implicações negativas à saúde humana, o excesso de ferro na água disponibilizada nas residências pode acarretar queixas da população, como amarelamento de roupas brancas, de louças sanitárias e azulejos, e conferir sabor e odor desagradáveis à água e alimentos com ela preparados (LIMA e PEDROZO, 2001). Além disso, a presença de águas ferruginosas resulta em provável perda da capacidade específica de poços profundos, porque o ferro quando se oxida pode precipitar, formando incrustações nas tubulações do poço e na caixa d'água armazenadora da água (Figura $1)$.

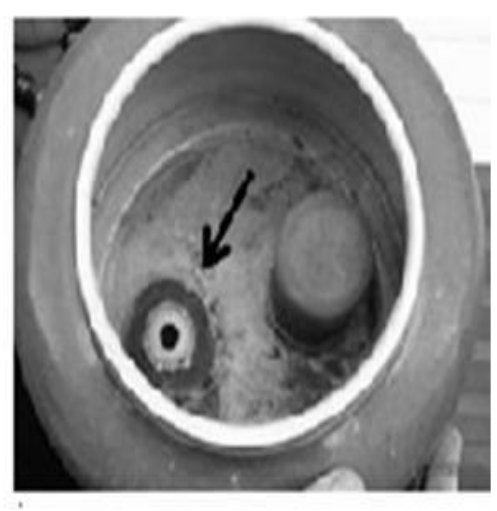

Figura 1 - Incrustação de ferro em uma caixa d'água e em um filtro de água Figure 1 - Iron fouling of a water tank and a water filter

Em função disso, a Resolução $\mathrm{n}^{\circ} 430$ do Conselho Nacional do Meio Ambiente - CONAMA (Brasil, 2011) e a Portaria n 2914 do Ministério da Saúde - MS (Brasil, 2011), estabelecem $0,3 \mathrm{mg} \mathrm{L}^{-1}$ como sendo a concentração máxima de ferro recomendável para água potável.

Existem vários métodos para a remoção do ferro utilizados no processo de purificação da água. Geralmente, essa remoção é induzida pela oxidação do ferro dissolvido ferroso e sua posterior precipitação como óxidos e oxi-hidróxidos de ferro. Com isso é frequente a co-remoção de impurezas inorgânicas e orgânicas presentes na água em função da elevada capacidade adsortiva dos 
oxi-hidróxidos de ferro precipitados (VAARAMAA e LEHTO, 2003; MUNTER et al., 2005). A aeração da água seguida de filtração é um dos métodos mais comuns, pouco dispendioso e comumente exequível em regiões nas quais ocorrem elevadas concentrações de ferro na água. Em algumas áreas na Índia, por exemplo, a população utiliza tradicionalmente sistemas de filtração de carvão/cinza e areia para remoção do ferro de águas ferruginosas, previamente aeradas (CHATURVEDI e DAVE, 2012). Isso pode se tornar uma alternativa em áreas desprovidas de tratamento de água e suprimento de água potável, quando identificada a presença de ferro em excesso na água consumida.

Entretanto, a análise química da concentração do ferro da água subterrânea através dos métodos clássicos de análise é geralmente pouco prática, mesmo que seja em uma pequena região região na qual essa água é consumida, em função da elevada quantidade de poços a serem avaliados. Além de dispendioso, a análise da água destes poços em laboratório envolve necessariamente uma logística bastante elaborada, principalmente quando uma avaliação em massa é considerada e as amostras precisam ser transportadas bem condicionadas, sem alterações da sua composição original.

Nesse contexto, o presente trabalho propõe o uso de um kit analítico otimizado para análises de ferro em águas subterrâneas, extensível a outras fontes de água (encanada ou de mananciais superficiais), e a metodologia para sua elaboração e uso. Sendo este kit analítico portátil, prático e de baixo custo, o mesmo permite a análise instantânea do nível de ferro da água subterrânea no local de coleta, com obtenção do resultado em poucos minutos. Assim, configura uma excelente ferramenta de caracterização da água de regiões desprovidas de sistemas de tratamento de água quanto ao seu teor de ferro. Esse tipo de avaliação pode gerar diagnósticos úteis para nortear planos municipais de saneamento básico e ações políticas que culminem com a melhoria da qualidade de vida e sanitária destas populações.

\section{METODOLOGIA}

\section{Elaboração do kit analítico \\ Fundamentação teórica}

$\mathrm{O}$ funcionamento do kit analítico baseiase na colorimetria visual, a partir de uma adaptação do método da fenantrolina, descrito em American Public Health Association - APHA (1998) e otimizado para águas subterrâneas, sem prejuízo para a análise de águas superficiais (PAIVA et al.,
2012). Nesse método, o ferro férrico $\left(\mathrm{Fe}^{+3}\right)$ presente na amostra é reduzido pela adição de uma solução redutora de cloridrato de hidroxilamina em meio ácido $(\mathrm{HCl})$, somando-se ao ferro ferroso $\left(\mathrm{Fe}^{+2}\right)$ originalmente presente na amostra. Com a adição da solução de 1,10-fenantrolina, ocorre a reação completa do ferro dissolvido (na faixa de pH 2,9 e 3,3, mantido pela ação de um tampão de acetato de amônio). Deste modo, três moléculas de fenantrolina quelam cada cátion de ferro ferroso para formar um composto alaranjado na amostra reagida.

Através da substituição do espectrofotômetro (utilizado para determinação colorimétrica de ferro) por um comparativo visual (tabela de diferentes tons da cor laranja, cada um associado com um nível de contaminação por ferro), é possível a determinação aproximada do nível de ferro dissolvido, forma preferencialmente absorvida por humanos (ZIMMERMANN et al., 2011), contida na amostra de água (análise qualitativa), seja essa subterrânea ou não.

O kit analítico aqui proposto foi baseado na estrutura dos kits disponibilizados no comércio pela LABCON TEST $^{\circledR}$ para água de aquários e pela PURTEST ${ }^{\circledR}$ para água de abastecimento domiciliar. Apesar do caráter qualitativo (não quantificam precisamente a concentração do analito), esses kits são amplamente difundidos em países da América do Norte, em função da praticidade e baixo custo para execução. Essas ferramentas alternativas para análise de água são disponibilizados no comércio para a determinação do $\mathrm{pH}$, da dureza, do nitrogênio amoniacal, do cobre e até mesmo para a indicação da presença de chumbo e dos herbicidas atrazina e simazina acima dos níveis estabelecidos pela Agencia de Proteção Ambiental dos Estados Unidos da América (United States Environmental Protect Agency - EPA).

A amostra testada com o kit para análise de ferro recebe reagentes incolores e, se contiver ferro, uma coloração laranja se desenvolve com intensidade proporcional à concentração de ferro. A relação da cor formada na amostra com o nível de ferro é feita a partir da comparação da amostra com uma tabela impressa que apresenta seis diferentes tons de laranja. Cada tom é associado a um nível de contaminação da água analisada (Figura 2). A partir da concentração máxima $(\mathrm{CM})$ de ferro estabelecida para águas potáveis $(\mathrm{CM}=0,3$ $\mathrm{mg} \mathrm{L}^{-1}$ ), estabeleceu-se que os três quadros superiores da cartela representam níveis inferiores à CM (águas não-ferruginosas), enquanto os três quadros inferiores representam níveis superiores à $\mathrm{CM}$ (águas ferruginosas). 


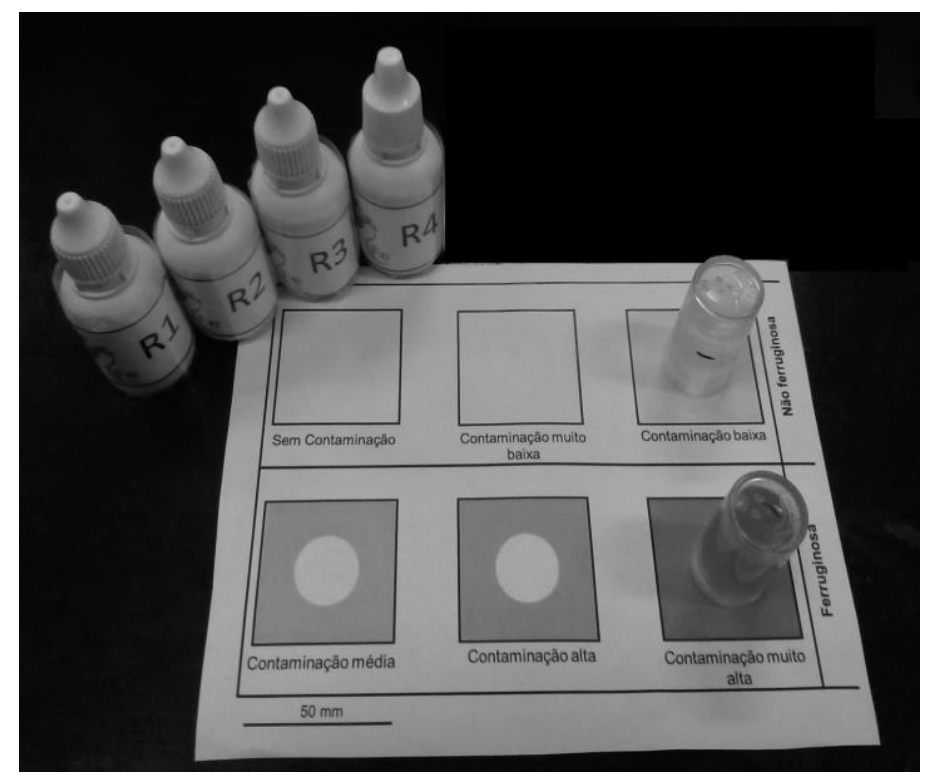

Figura 2 - Imagem do kit analítico para ferro, incluindo a cartela com tabela de cores relacionadas aos seis níveis de ferro. Na foto também estão apresentadas duas amostras submetidas à avaliação

Figure 2 - Iron water test kit, including the colors chart

\section{Preparo dos reagentes}

Para o desenvolvimento da reação supracitada são necessários quatro reagentes. Estes devem ser dispostos em frascos opacos, tipo conta-gotas de $25 \mathrm{~mL}$ e identificados por $\mathrm{R}_{1}, \mathrm{R}_{2}, \mathrm{R}_{3} \mathrm{e}$ $\mathrm{R}_{4}$, como esquematizado na figura 3 . Os reagentes correspondentes a cada numeração estão descritos a seguir, assim como os respectivos procedimentos de preparo.

- $\mathrm{R}_{1}$ : ácido clorídrico de pureza analítica (HCl p.a.).

- $\mathrm{R}_{2}$ : solução de hidroxilamina - dissolver $20 \mathrm{~g}$ de cloridrato de hidroxilamina $\left(\mathrm{NH}_{2} \mathrm{OH} \cdot \mathrm{HCl}\right)$ em $100 \mathrm{~mL}$ de água destilada.

- $\mathrm{R}_{3}$ : solução de ortofenantrolina - dissolver $200 \mathrm{mg}$ de 1,10-fenantrolina monohidratada $\left(\mathrm{C}_{12} \mathrm{H}_{8} \mathrm{~N}_{2} \cdot \mathrm{H}_{2} \mathrm{O}\right)$ em $100 \mathrm{~mL}$ de água com agitação e aquecimento a $80^{\circ} \mathrm{C}$. - $\mathrm{R}_{4}$ : solução tampão de acetato de amônio - dissolver $250 \mathrm{~g}$ de acetato de amônio $\left(\mathrm{NH}_{4} \mathrm{C}_{2} \mathrm{H}_{3} \mathrm{O}_{2}\right)$ em $75 \mathrm{~mL}$ de água destilada. Adicionar $350 \mathrm{~mL}$ de ácido acético glacial de pureza analítica $\left(\mathrm{CH}_{3} \mathrm{COOH}\right.$ p.a.) e homogeneizar.

\section{Constituintes do kit analítico}

- Quatro frascos contendo os reagentes $\left(\mathrm{R}_{1}\right.$ a $\left.\mathrm{R}_{4}\right)$, conforme preparação descrita no item anterior (Figura 3);

- Um frasco de plástico transparente para a reação durante a análise, de formato cilíndrico (tipo proveta), contendo um menisco de $5 \mathrm{~mL}$ e uma tampa de encaixe na cor branca ou transparente (Figura 4);

- Cartela de gradação de cores impressa e plastificada.

- Manual de uso, ou seja, um roteiro de procedimentos, no qual consta a descrição de seis ações consecutivas para efetivar a reação colorimétrica (ver item a seguir);

- Um par de luvas cirúrgicas para o procedimento analítico e manipulação dos reagentes e da amostra após a reação.

Embora não seja indispensável, recomenda-se o acondicionamento de todo material acima descrito em uma caixa não metálica com tampa, o que facilita o transporte do kit e torna o seu uso mais prático.

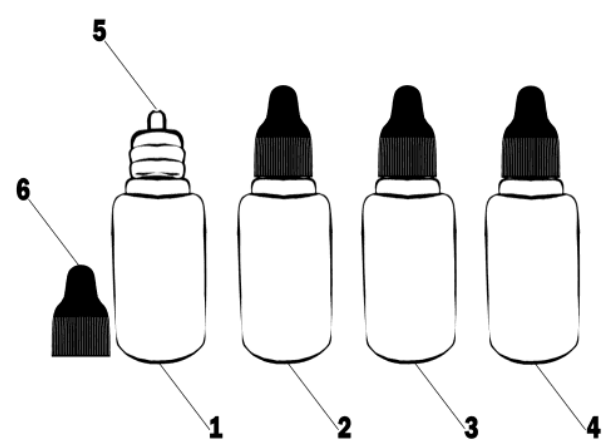

Figura 3 - Esquema dos frascos de reagentes constituintes do kit analítico. Números de 1 a 4 = frascos; 5= bico dosador de gotas; $6=$ tampa de rosca.

Figure 3 - Schema of reagent bottles used for the kit. Number from 1 to $4=$ bottles; $5=$ dropper tip and $6=$ screw cap. 


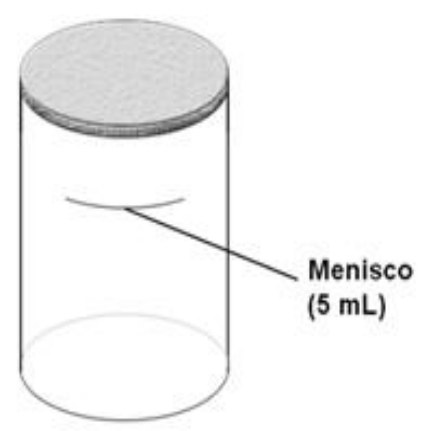

Figura 4 - Frasco plástico para a reação, onde deve ser inserida a amostra e os reagentes. $\mathrm{O}$ menisco $(5 \mathrm{~mL})$ também está apresentado

Figure 4 - Schema of the plastic reaction flask, wherein the sample and the reagents are placed. The meniscus $(5 \mathrm{~mL})$ is also presented

\section{Manual de uso do kit analítico}

Usando luvas, coletar a água subterrânea ( $5 \mathrm{~mL}$ ) no frasco de análise (Figura 4), até a linha de indicação do volume. Imediatamente após a coleta, adicionar:

- 2 gotas de $\mathrm{R}_{1}$

- 4 gotas de $R_{4}$, tampar e agitar o frasco;

- 6 gotas de $R_{2}$;

- 6 gotas de $\mathrm{R}_{3}$, tampar e agitar o frasco.

Esperar dez minutos, virar o frasco de análise com a tampa voltada para baixo e comparar a cor formada na amostra com a cartela contendo a tabela de cores.

\section{Montagem da tabela de cores}

A fim de construir o comparativo visual (tabela de cores) e verificar a viabilidade da apli- cação do kit aqui proposto, foram analisados seis padrões de ferro com concentrações crescentes de 0,$1 ; 0,2 ; 0,3 ; 1,0 ; 4,0$ e $10 \mathrm{mg} \mathrm{L}^{-1}$ e a prova em branco (análise da água ultra pura). A matriz de diluição para preparar os padrões foi uma solução aquosa de sulfato ferroso amoniacal (PAIVA et al., 2012). Foram também analisadas seis amostras de água subterrânea coletadas aleatoriamente.

Cada um dos padrões e das amostras foi separado em duas alíquotas, cada uma analisada por um método de análise de ferro: uma submetida aos procedimentos descritos para uso do kit aqui proposto (item Constituintes do kit analítico) e a outra, aos procedimentos do método instrumental (PAIVA et al., 2012). A partir da leitura das absorbâncias dos padrões em espectrofotômetro (510 nm de comprimento de onda), foram construídas duas curvas de calibração (retas padrão - absorbância versus concentração), uma para cada método e determinada a respectiva equação da reta padrão. Quanto as amostras, as duas alíquotas de cada uma foram igualmente lidas em espectrofotômetro e, a partir da equação da reta obtida com os padrões analisados pelo kit e da equação da reta obtida com os padrões analisados pelo método instrumental, obteve-se para cada amostra duas concentrações de ferro em mg $\mathrm{L}^{-1}$ resultantes da análise por cada um dos dois métodos.

Os resultados obtidos estão apresentados na tabela 1. A recuperação do método do kit em relação ao método laboratorial foi em média de $88 \pm 16 \%$, comprovando a validade do kit em termos metodológicos.

Tabela 1 - Resultados dos testes de avaliação do kit: A) Entre os diferentes métodos e B) por diferentes observadores

Table 1 - Kit evaluation test results: A) Among the different methods and B) by different observers

\begin{tabular}{ccccc}
\hline \multicolumn{2}{c}{ Concentração de Ferro $\left(\mathbf{m g ~ L}^{-1}\right)^{\mathbf{A}}$} & \multicolumn{3}{c}{ Nível de Ferro ${ }^{\mathbf{B}}$} \\
\hline Método laboratorial & Kit analítico & Observador 1 & Observador 2 & Observador 3 \\
\hline 2,9 & 2,7 & 5 & 5 & 5 \\
9,0 & 7,0 & 6 & 6 & 6 \\
1,0 & 0,7 & 4 & 4 & 4 \\
0,1 & 0,1 & 3 & 3 & 3 \\
1,7 & 1,4 & 4 & 4 & 4 \\
4,1 & 4,8 & 6 & 6 & 6 \\
\hline
\end{tabular}

A partir das alíquotas dos padrões submetidas aos procedimentos descritos para o kit, obteve-se um gradiente de tons da cor laranja. Através de um software gráfico, esse gradiente de cor foi reproduzido em uma tabela de cores (cujas propriedades que permitem a fiel reprodução das cores estão apresentadas na tabela 2), sendo cada tom associado a um nível de ferro na água ("sem contaminação", "contaminação muito baixa", "contaminação baixa", "contaminação média", "contaminação alta" e "contaminação muito alta"), conforme esquematizado na figura 5. Ao re- 
produzir a cartela de cores, é importante manter um círculo em branco (cujas dimensões devem corresponder às do frasco utilizado para reação) em cada um dos quadros referentes a cada nível, como apresentado na figura 2. Sobre esse círculo deve ser colocado o frasco contendo a amostra reagida.

Tabela 2 - Propriedades dos tons de laranja que compõem a tabela de cores e os respectivos níveis de ferro associados

Table 2 - Properties of the colors that compose the color chart and their associated iron levels

\begin{tabular}{lcccccc}
\hline \multirow{2}{*}{ Propriedades da cor } & \multicolumn{7}{c}{ Níveis de ferro $^{\mathrm{a}}$} \\
\cline { 2 - 7 } & 1 & 2 & 3 & 4 & 5 & 6 \\
\cline { 2 - 7 } Matiz & 160 & 20 & 20 & 20 & 21 & 20 \\
Saturação & 0 & 240 & 240 & 240 & 206 & 240 \\
Luminosidade & 240 & 225 & 215 & 183 & 168 & 120 \\
Vermelho & 255 & 255 & 255 & 255 & 244 & 255 \\
Verde & 255 & 239 & 228 & 193 & 181 & 127 \\
Azul & 255 & 223 & 202 & 134 & 112 & 0 \\
\hline
\end{tabular}

a Os números de 1 a 6 correspondentes a: "sem contaminação", "contaminação muito baixa", "contaminação baixa", "contaminação média", "contaminação alta" e "contaminação muito alta", respectivamente.

a The numbers 1 to 6 corresponding to: "uncontaminated", "very low contamination", "low contamination", "average contamination", "high contamination" and "very high contamination", respectively

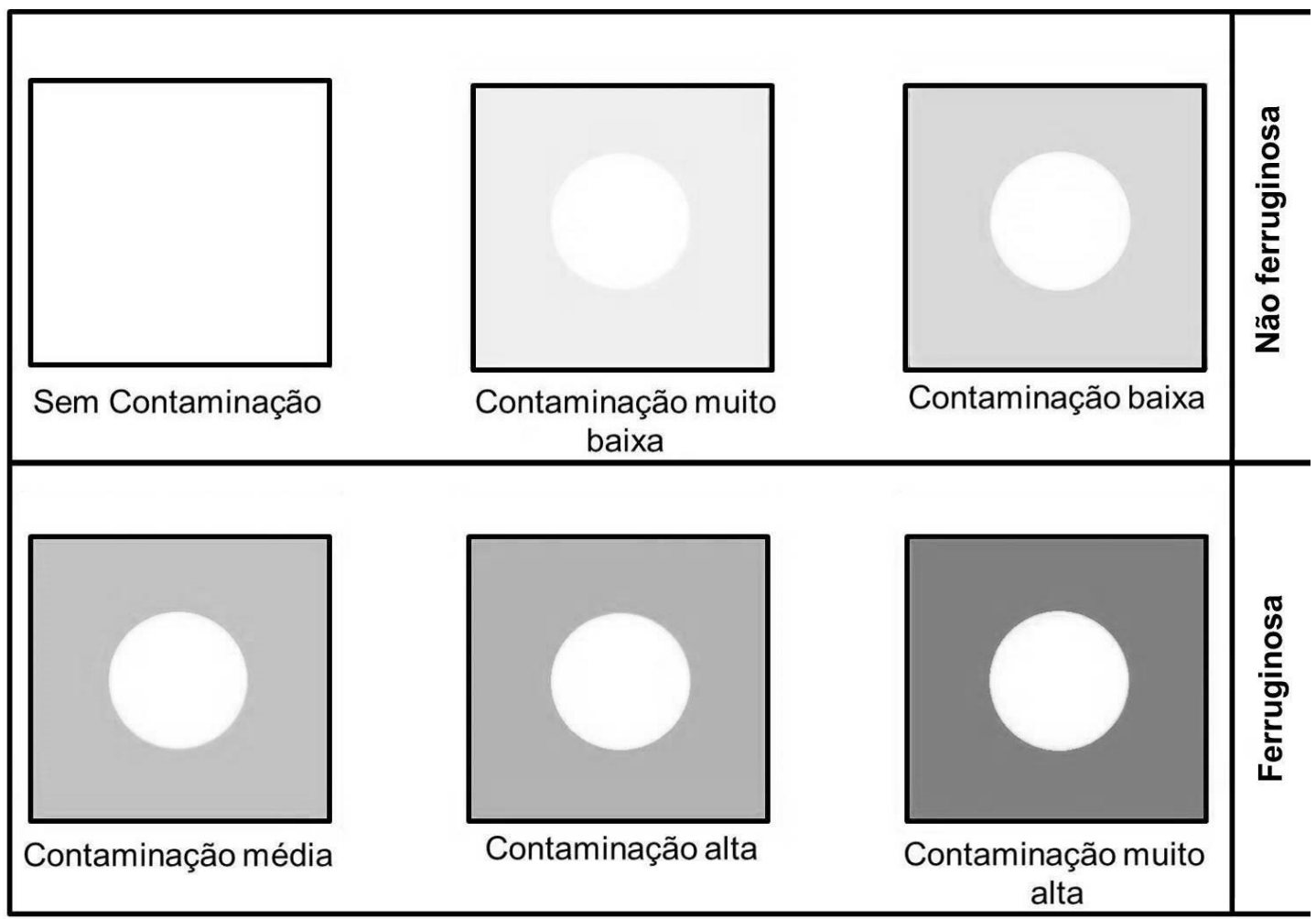

$50 \mathrm{~mm}$

Figura 5 - Cartela contendo a tabela de cores de diferentes tons da cor laranja e os níveis de ferro correspondentes Figure 5 - Color chart with six shades of orange and their corresponding iron levels

Para testar a viabilidade do uso da tabela colorimétrica por um usuário leigo, cada uma das amostras submetidas ao procedimento descrito para o kit foi comparada com os tons da tabela por três observadores escolhidos aleatoriamente e que desconheciam o objetivo do teste, obtendo-se resultados exatamente iguais e comprovando-se assim a reprodutibilidade do método proposto com o uso deste kit analítico. 


\section{Avaliação da eficiência da aplicação do kit analítico em uma área sem suprimento de água tratada \\ Metodologia}

Área de estudo

O kit analítico foi aplicado em uma área piloto: uma ilha pertencente ao município de Rio Grande (Rio Grande do Sul), na qual a única fonte de água disponível para a totalidade de sua população é a água subterrânea, extraída em poços residenciais e utilizada sem tratamento prévio.

A Ilha dos Marinheiros possui cerca de 1324 habitantes e 468 residências, distribuídos em $40 \mathrm{~km}^{2}$ de área, segundo o Instituto Brasileiro de Geografia e Estatística - IBGE (BRASIL, 2010). Por estarem inseridas no estuário da Lagoa dos
Patos, na região costeira do Rio Grande do Sul, as águas que a margeiam são estuarinas e salinidade variável (água doce, salobra ou salina), dependendo da hidrodinâmica do estuário (WINDOM e NIENCHESKI, 2003). Os ilhéus vivem essencialmente da pesca e da agricultura familiar e suas casas encontram-se às margens da única estrada existente ao redor da ilha, já que no centro existem dunas de areias, matas artificiais de Pinus sp. ou de vegetação nativa, além de lagoas de afloramento de águas subterrâneas (Figura 6).

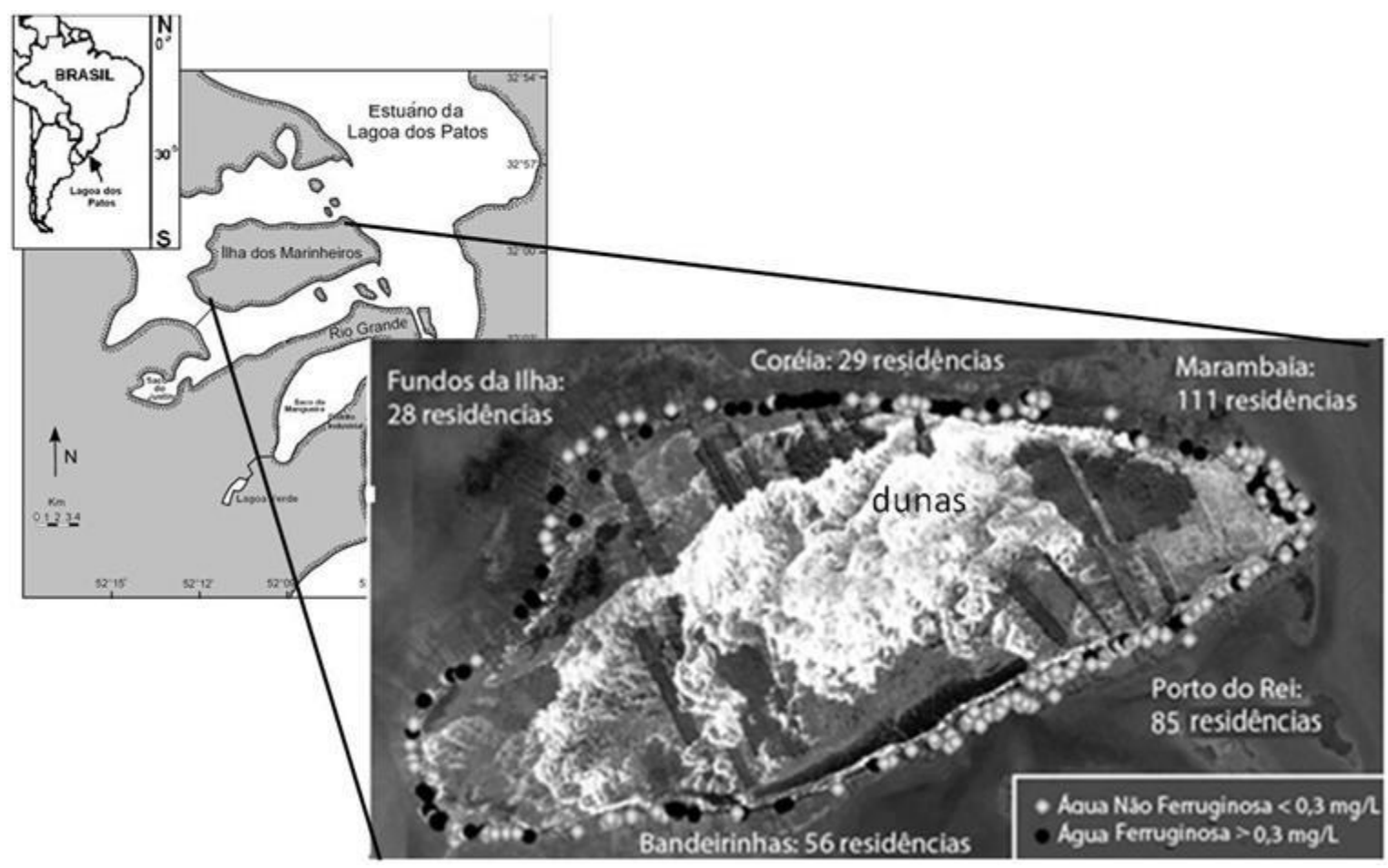

Figura 6 - Ilha dos Marinheiros, localizada no estuário da Lagoa dos Patos (RS). As localizações de cada residência $(n=309)$, bem como os respectivos resultados também estão apresentados, sendo os círculos pretos referentes a locais com água ferruginosa e os círculos brancos, locais com água não ferruginosa

Figure 6 - Marinheiros Island, located in Patos Lagoon Estuary (RS). The location of each house $(n=309)$ and its water results are also presented. Non-rusty waters are indicated by white circles and rusty waters by black circles

Estratégia de amostragem na ilha

Das 468 residências existentes na ilha, 309 tiveram a água que consomem analisada durante 20 dias de amostragem, distribuídos ao longo de 2012 (Figura 6), sendo que as demais residências não estavam habitadas durante os dias de amostragem.

Com o uso do kit analítico descrito neste trabalho, foi analisado em cada residência o nível de ferro da água coletada da torneira da cozinha de cada residência e em outra alíquota da amostra foi medido o pH, com o uso de um potenciômetro digital portátil (pHmetro Digimed DM-22). Todas as residências avaliadas foram georreferenciadas com um GPS 76 Marine Navigator Garmin.

Complementando o estudo, foram fornecidos aos moradores um laudo impresso contendo o resultado da análise da água, além de um livreto ilustrado com textos enfocando: (i) a problemática 
do consumo de água ferruginosa e (ii) sugestões de métodos caseiros acessíveis de remoção do ferro da água subterrânea. Foram também efetuados levantamentos de dados referentes à profundidade do poço e à proximidade deste à fossa sanitária de cada residência, além de questionados alguns aspectos sócio-ambientais dos moradores.

Resultados e discussão da aplicação proposta do kit analítico

O uso do kit analítico em larga escala na Ilha dos Marinheiros permitiu que cada uma das cinco áreas da ilha fosse caracterizada com os respectivos percentuais de ocorrência de água ferruginosa, ou seja, cuja concentração de ferro na água foi superior ao limite estabelecido pela legislação vigente.

Os resultados evidenciaram as áreas onde os níveis de ferro foram maiores e mais preocupantes. A área com destacado percentual de inci- dência de água ferruginosa (classificadas nos três últimos níveis da tabela de cores) foi a Coréia, com 79,3\% das suas residências utilizando água ferruginosa. Com percentuais em ordem decrescente seguiram-se as áreas: Marambaia (50,5\%), Fundos da Ilha (50\%), Bandeirinhas $(42,9 \%)$ e Porto do Rey $(14,1 \%)$. Esses resultados apontam e documentam as áreas nas quais a atuação do poder público deve ser concentrada para efetivar a melhoria da qualidade de vida dos ilhéus.

Nesse sentido, constatou-se que as residências avaliadas em que havia filtros portáteis com vela de cerâmica, a água filtrada teve uma redução significativa do nível de ferro (Figura 7). Esses resultados demonstram a eficiência da filtração da água na remoção do ferro, o que pode torná-la, em muitos casos, potável, além de enfatizar a noção de que medidas simples podem solucionar essa questão.

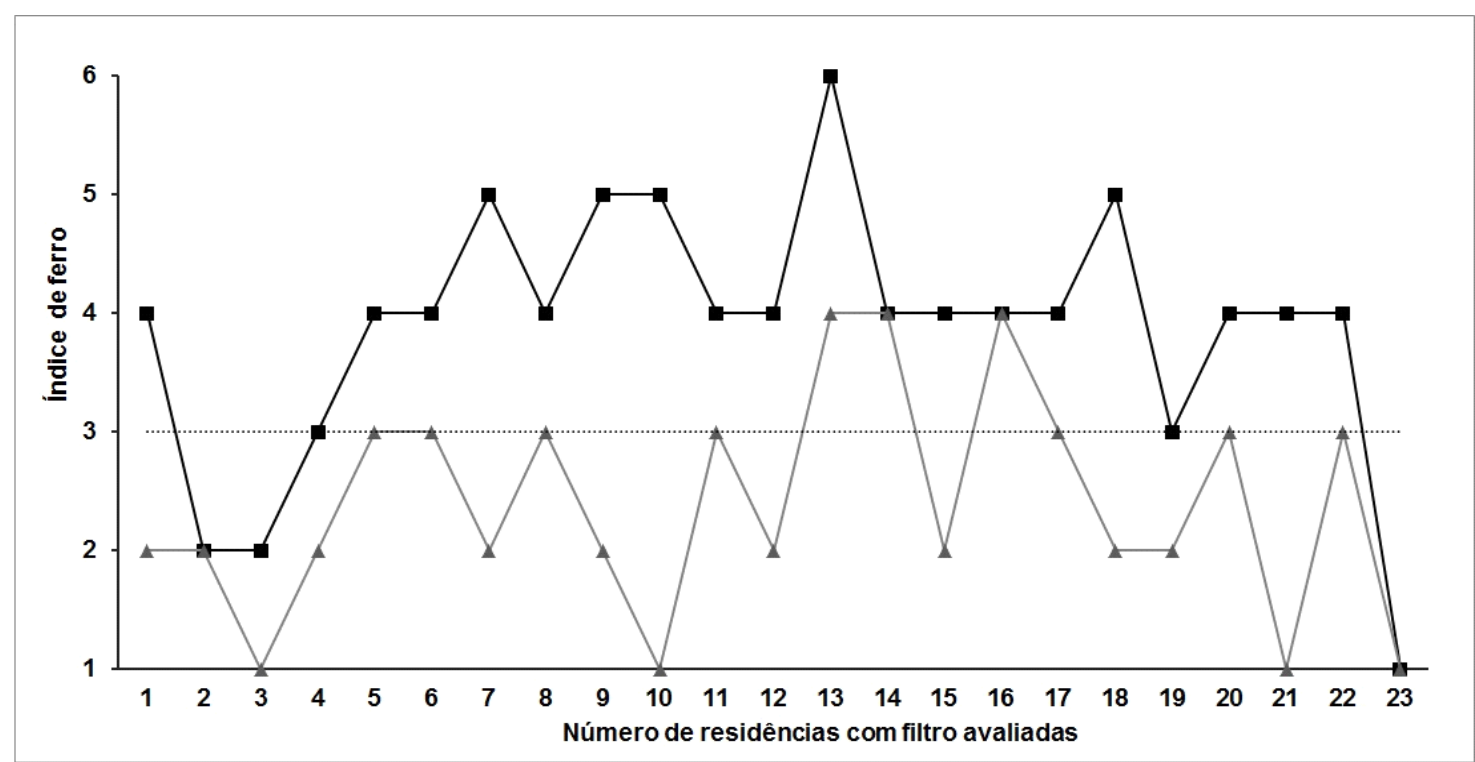

Figura 7 - Eficiência do uso de filtros na remoção de ferro da água $(n=23)$. Os quadrados indicam o níve de ferro antes (preto) e depois (cinza) da filtração e a linha pontilhada indica o limite máximo de ferro recomendado para água potável

Figure 7 - Iron removal efficiencies of filter usage $(n=23)$. Squares indicate the iron levels before (black) and after (grey) the filtration, and the dotted line indicates the maximum contaminant level for iron in drinking water

A associação dos níveis de ferro com os respectivos valores de $\mathrm{pH}$ da água consumida em cada residência sugere a tendência do aumento da concentração do ferro na água com a diminuição do $\mathrm{pH}$, o que foi mais evidenciado na área Bandeirinhas (Figura 8), corroborado pela significativa correlação inversa entre os níveis de ferro (para o teste numerado de 1 a 6) e de pH (Correlação de Spearman: $\mathrm{r}=-0,55 ; \mathrm{n}=54)$. A acidificação das águas do lençol freático pode portanto ter como efeito uma das causas do enriquecimento de ferro, por favorecer a dissolução do ferro presente no solo. A acidificação pode ser causada pela presença de ferrobactérias que acidificam a água a partir da respiração (LIMA e PEDROZO, 2001), além da presença de matas de Pinus sp., que diminuem a oxigenação dos solos em função do depósito de acículas em decomposição sobre a superfície dos mesmos (WALLY et al, 2010). 


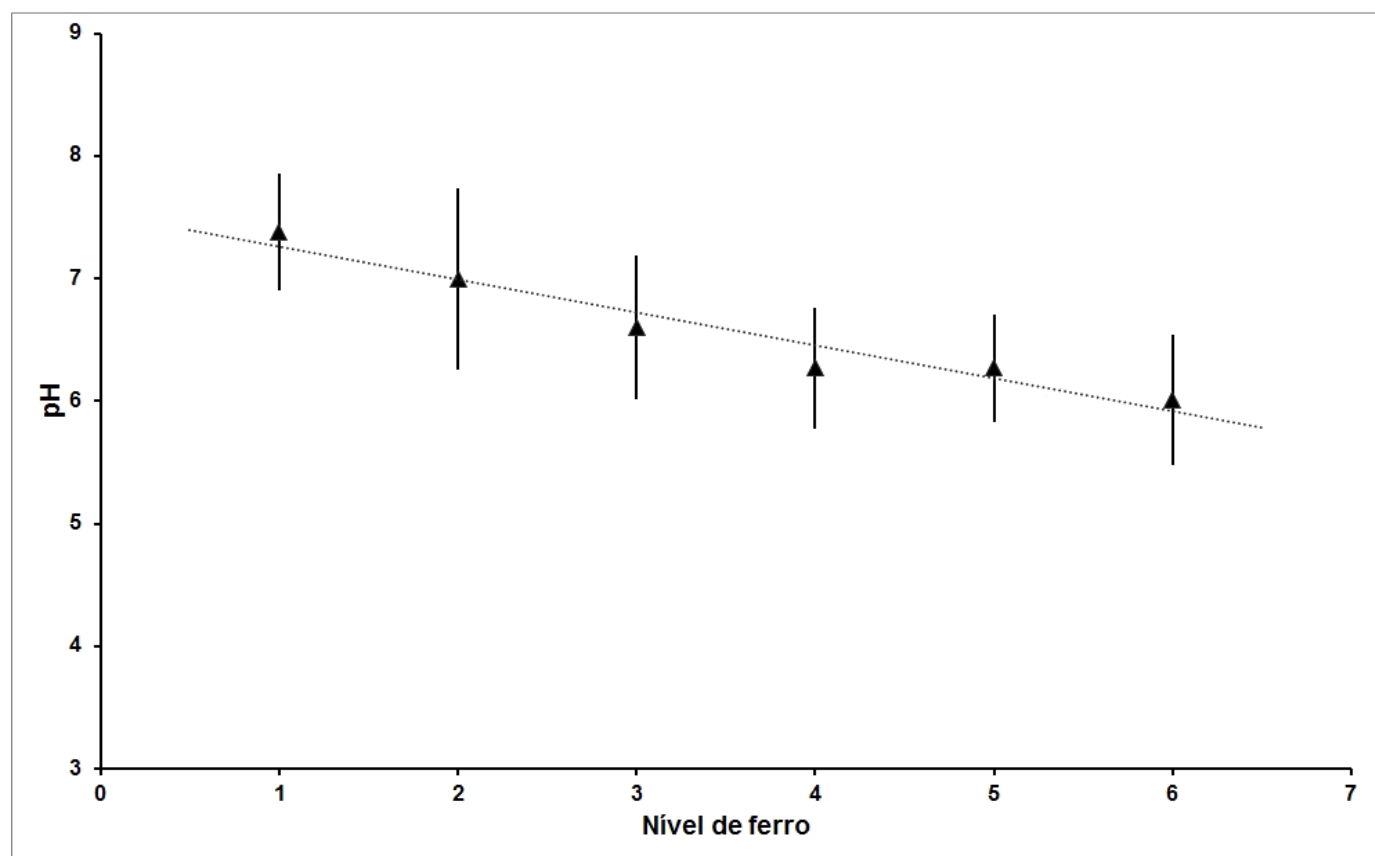

Figura 8 - Níveis de ferro vs. valores médios de $\mathrm{pH}$ das águas analisadas $(\mathrm{n}=54)$ em uma das áreas da Ilha dos Marinheiros. A linha pontilhada indica a tendência do nível de ferro em relação à variação dos valores de $\mathrm{pH}$ e as linhas solidas indicam o desvio- padrão do $\mathrm{pH}$

Figure 8 - Levels of iron vs. $\mathrm{pH}$ values of the waters from one of the Marinheiros Island's areas $(\mathrm{n}=54)$. The dotted line indicates the linear trend between the iron levels and the $\mathrm{pH}$ values and the solid lines indicate the standard deviation of the $\mathrm{pH}$

A partir das constatações obtidas na Ilha dos Marinheiros, da distribuição espacial e da avaliação individual dos níveis de ferro, houve motivação da adoção de medidas eficientes e viáveis, tanto particularmente pela comunidade como pelo poder público, na busca de melhores condições de vida para os ilhéus.

Nesse sentido, a Prefeitura Municipal da cidade do Rio Grande, incitada pelos próprios moradores da comunidade da ilha, pôde incluir o problema do consumo da água ferruginosa no seu Plano Municipal de Saneamento Básico, Produto 3 (ENGEPLUS, 2013). Assim, foram propostas oficialmente duas alternativas para a Ilha dos Marinheiros: implantação de dois poços profundos de acesso público na ilha e/ou incentivo e apoio técnico e financeiro para a utilização de cisternas armazenadoras de água da chuva. Portanto, o uso do kit analítico aqui proposto permitiu a avaliação em massa dos níveis de ferro na comunidade, individualmente por residência o que foi uma ferramenta importante no processo da conscientização e mobilização dos moradores da ilha no sentido de buscarem soluções.

Conclusão da aplicação proposta do kit analítico em comunidades carentes de água potável

O kit analítico permitiu a avaliação dos níveis de ferro na água de cada residência da Ilha dos Marinheiros em um curto período de amos- tragem. Isso foi uma ferramenta importante no processo da conscientização e mobilização dos moradores no sentido de buscarem soluções individuais ou comunitárias. O diagnóstico gerado com os dados obtidos em cada residência possibilitou a atuação dos órgãos públicos na elaboração de estratégias que contemplam o problema da comunidade e culminarão na melhoria na qualidade da água consumida pela população.

A grande variabilidade das concentrações de ferro detectadas nos poços de uma mesma área mostrou que cada poço perfurado deve ser avaliado quanto ao teor de ferro dissolvido antes do seu uso como fornecedor de água para consumo, mesmo que se situe próximo a outros poços que contenham água de boa qualidade. Nesse sentido, este kit analítico é muito prático em função da facilidade de uso e fornecimento de resultados instantâneos.

\section{CONCLUSÃO GERAL}

O kit analítico simplificado para análise de ferro apresenta diversas vantagens. Estas estão relacionadas à facilidade de confecção, ao custo reduzido e, ainda, à facilidade de operação por pessoas não necessariamente treinadas para a realização de análises químicas, gerando resultados confiáveis e instantâneos. 
A aplicação deste kit analítico evidenciou que o mesmo é muito adequado para avaliação da qualidade da água consumida numa área carente de água potável, principalmente quando a água subterrânea é utilizada para tal fim.

Isso permite a recomendação de sua reprodução por outras equipes para aplicações em projetos comunitários, principalmente em periferias de municípios onde não há acesso a água potável canalizada, ou até mesmo para fins didáticos em projetos de educação ambiental relacionados com qualidade da água.

\section{REFERÊNCIAS}

AMERICAN PUBLIC HEALTH ASSOCIATION (APHA). Standard methods for the examination of water and wastewater. Washington (DC): American Health Association Inc., 1998.

BALMADRID, C.; BONO, M. Recognizing and managing iron toxicity. Emergency Medicine, Virginia, n. 41, p. $36-41,2009$.

BRASIL. Conselho Nacional do Meio Ambiente (CONAMA). Resolução $n^{\circ} 430$ de 16 de maio de 2011. Dispõe sobre condições e padrões de lançamento de efluentes, complementa e altera a Resolução n 357 , de 17 de março de 2005, do Conselho Nacional do Meio Ambiente - CONAMA. Diário Oficial da União, Brasília, v.92, p. 89 p, 16 maio 2011, Seção 1.

INSTITUTO BRASILEIRO DE GEOGRAFIA E ESTATísTICA (IBGE). Censo Demográfico. Características gerais da população, religião e pessoas com deficiência. 2010.

BRASIL. Ministério da Saúde. Portaria nº 2.914 de 14 de dezembro de 2011. Dispõe sobre os procedimentos de controle e de vigilância da qualidade da água para consumo humano e seu padrão de potabilidade. Diário Oficial da União, Brasília, v. 239, p.39 - 46, 14 dez. 2011, Seção 1.

CHATURVEDI, S.; DAVE, P. Removal of iron for safe drinking water. Desalination. Elsevier B.V. Gujarat India., v. 303, p. 1-11, 2012.

CORBETT, J.V. Accidental poisoning with iron supplements. MCT - The American Journal of Maternal Child Nursing. PubMed, São Francisco., v. 20 (4): p 234. 1995.

DEVLIN, T.M. Manual de Bioquímica com Correlações Clínicas. São Paulo: Edgard Blucher Ltda., 2007.

Engenharia e Consultoria Ltda. - ENGEPLUS. Contrato n 134/2012/SMMA. Plano Municipal de Saneamento Básico (PMSB) do Município de Rio Grande. Prognóstico e proposição de alternativas para o Sistema de Saneamento (Produto 3). Tomo I: Abastecimento de

\section{AGRADECIMENTOS}

Os autores agradecem ao Ministério da Educação (MEC) pelo suporte financeiro para as amostragens na Ilha dos Marinheiros, à Diretoria de Extensão da FURG (DIEX) e à Secretaria da Saúde de Rio Grande pela logística e apoio. Mariele Paiva agradece à Coordenação de Aperfeiçoamento de Pessoal de Nível Superior (CAPES) pela bolsa concedida.

água e esgoto sanitário. Rio Grande: 2013. Prefeitura Municipal de Rio Grande.

FOOD AND NUTRITION BOARD. Committee on Diet and Health - Diet and health: implications for reducing chronic disease risk. Washington, DC: National Academy Press, 1989.

LIMA, I. V. e PEDROZO, M.F. Ecotoxicologia do ferro e seus compostos. Série Cadernos de Referência Ambiental. Salvador, Bahia: Centro de Recursos Ambientais (CRA), 2001.

MAHAN, D.C.; CHING, S. e DABROWSKI, K. Developmental aspects and factors influencing the synthesis and status of ascorbic acid in the pig. Annu Rev. Nutr., v. 24, p.. $79-103,2004$.

MUNTER, R.; OJASTE, H. e SUTT, J. Complexed iron removal from ground water.J. Environ. Eng. 131, p. 1014-1020. 2005.

PAIVA, M.L.; BAUMGARTEN, M.G.Z e WALLY, M.K. Especiação do ferro em águas subterrâneas: otimização do método espectrofotométrico na região da luz visível. Revista Analytica.São Paulo: Eskalab: n 57, p. 60-66, 2012.

ROBERTSON, A. e TENENBEIN, M. Hepatotoxicity in acute iron poisoning. Human \& experimental toxicology, n. 24, p. $559-562,2006$.

SKOCZYNSKA, A.; KWIECINSKA, D.; KIELBINSKI, M. e ELUKASZEWSKI, M. Acute iron poisoning in adult female. Human \& experimental toxicology, n. 26, p. 663 - 666, 2007.

VAARAMAA, K. e LEHTO, J. Removal of metals and anions from drinking water by ion exchange. Desalination, v.155, p. 157-170. 1984.

VODYANITSKII, Y. N. E PLEKHANOVA, I. O. Biogeochemistry of Heavy Metals in Contaminated Excessively Moistened Soils (Analytical Review). Eurasian Soil Science, v. 47, n. 3, p. 153-161, 2014.

WALLY, M.K.; BAUMGARTEN, M.G.Z.; CASARTELLI, M.R. e PAIVA, M.L. Influência das areas florestadas 
por Pinus sp. (Ilha dos Marinheiros, Rio Grande/RS) no enriquecimento em ferro da água subterrânea. In: XXII Semana Nacional de Oceanografia, 2010.

WINDOM, H. e NIENCHESKI, L.F.H. Biogeochemical processes in a freshwater - seawater mixing zone in permeable sediments along the coast of Southern Brazil. Marine Chemistry, Elsevier, v. 83, p. 1211 - 130, 2003.
ZIMMERMANN, M. B., BIEBINGER, R. EGLI, I., ZEDER, C. E HURRELL, R. F. Iron deficiency upregulates iron absorption from ferrous sulphate but not ferric pyrophosphate and consequently food fortification with ferrous sulphate has relatively greater efficacy in iron-deficient individuals. British journal of nutrition, v. 105, n. 8, p. 1245 - 1250, 2011. 